\title{
Cutaneous infection by Mycobacterium fortuitum
}

\section{Verónica Rotela, Maria Elena Ibáñez, Beatriz Di Martino Ortiz, Oilda Knopfelmacher Domínguez, Mirtha Rodríguez Masi, Lourdes Bolla Argüello de Lezcano}

Department of Dermatology, Faculty of Medical Sciences, Clinicas Hospital, National University of Asuncion, Paraguay

Corresponding author: Prof. Dra. Beatriz Di Martino Ortiz, E-mail: beatrizdimartino@gmail.com

\begin{abstract}
Mycobacteria are aerobic, non-spore forming, gram positive, acid-fast bacilli, which affect skin, subcutaneous tissue, and other organs and systems. Mycobacterium fortuitum produces cellulitis, abscesses, papules-pustules, nodules and ulcers with serosanguinolent, purulent material, and subcutaneous necrosis. A 61-year-old woman, presents a case of two months of evolution that begins with reddish grain from an insect sting. After immersion in the Mexican Sea, it worsens, increases in quantity, is blistered and has brownish secretion; Physical examination shows erythematous plaque, with punctate orifices with hematic and meliceric crusts; Pustules and satellite papules, on the anterior aspect of the right leg. Histopathology: Suppurative dermal granulomas, centered by acute leukocyte infiltrate, with liquefactive tissue necrosis, surrounded by chronic inflammation with macrophages, plasma cells, lymphocytes, multinucleated giant cells. The first skin culture returns negative; in the second skin culture, fast-growing, non-pigmented atypical mycobacteria. Molecular detection is performed by Polymerase Chain Reaction: Mycobacterium fortuitum. Treatment with Ciprofloxacin $500 \mathrm{mg}$ every 12 hours, with resolution of the table to the eighth month. A case of cutaneous infection by Mycobacterium fortuitum, related to the immersion in the sea and corals, whose diagnostic process has been difficult and was achieved by techniques of advanced molecular biology.
\end{abstract}

Key words: Atypical mycobacteria; Mycobacterium fortuitum; Infections 


\title{
Infeccion cutanea por Mycobacterium fortuitum
}

\author{
Verónica Rotela, Maria Elena Ibáñez, Beatriz Di Martino Ortiz, \\ Oilda Knopfelmacher Domínguez, Mirtha Rodríguez Masi, \\ Lourdes Bolla Argüello de Lezcano
}

Department of Dermatology, Clinicas Hospital, Faculty of Medical Sciences, National University of Asuncion, Paraguay

Corresponding author: Prof. Dra. Beatriz Di Martino Ortiz, E-mail: beatrizdimartino@gmail.com

\begin{abstract}
RESUMEN
Las micobacterias son bacilos aerobios, no formadores de esporas, gram + , Bacilo Acido-Alcohol Resistentes que afectan piel, tejido celular subcutáneo, y otros órganos y sistemas. Mycobacterium fortuitum produce celulitis, abscesos, pápulo-pustulas, nódulos o úlceras con material sero-sanguinolento, purulento, y necrosis subcutánea. Mujer de 61 años, presenta 2 meses de evolución que inicia con grano rojo por picadura de insecto, luego de la inmersión en el mar en México empeora, aumenta en cantidad, se ampollan y presentan secresión amarronada; al examen físico presenta eritematosa, con orificios puntiformes con costras hemáticas y melicéricas; pústulas y pápulas satélites; en cara anterior de pierna derecha. Histopatología: Granulomas dérmicos supurativos, centrados por infiltrado leucocitario agudo, con necrosis licuefactiva tisular, rodeados de inflamación crónica con macrófagos, plasmocitos, linfocitos, células gigantes multinucleadas. El primer cultivo de piel retorna negativo, en el segundo cultivo de piel se aísla Micobacteria atípica no pigmentada de crecimiento rápido; se realiza detección molecular por Reacción en cadena de Polimerasas: Mycobacterium fortuitum. Se realiza tratamiento con Ciprofloxacina $500 \mathrm{mg}$ cada 12 hs, con resolución del cuadro al octavo mes. Se presenta un caso de infección cutánea por Mycobacterium fortuitum, relacionado a la inmersión en el mar y corales, cuyo proceso diagnóstico ha sido dificultoso y se logró mediante técnicas de avanzada biología molecular.
\end{abstract}

Palabras claves: Micobacterias atípicas, Mycobacterium fortuitum, Infecciones

\section{INTRODUCCION}

Las infecciones por micobacterias atípicas se encuentran en constante aumento, y afectan piel, tejido celular subcutáneo, y otros órganos y sistemas [1]. Son de distribución mundial, se encuentran en la naturaleza colonizando agua, suelo, material vegetal, aire, animales, plantas o material quirúrgico. Son saprófitos, oportunistas en el hombre y no se transmiten de persona a persona $[2,3]$.

La transmisión puede realizarse a través de las vías respiratoria y digestiva, o mediante inoculación directa en el caso de la piel, o por diseminación hematógena a partir de un foco visceral [1].
Este género incluye a M. tuberculosis, M. bovis, M. africanum, M. microti, M. leprae y un grupo de micobacterias denominadas atípicas, no patógenas en individuos sanos, pero si en condiciones de inmunosupresión, sobre todo por el incremento de pacientes inmunocomprometidos, el virus de la inmunodeficiencia humana y los tratamientos inmunosupresores. Las lesiones cutáneas pueden constituir el primer o único signo de infección [2].

Son bacilos delgados de forma recta o ligeramente curvada, aerobios, inmóviles, no formadores de esporas, difíciles de teñir con la tinción de Gram, aunque se consideran gram positivos. Resisten la decoloración en las tinciones con ácido-alcohol

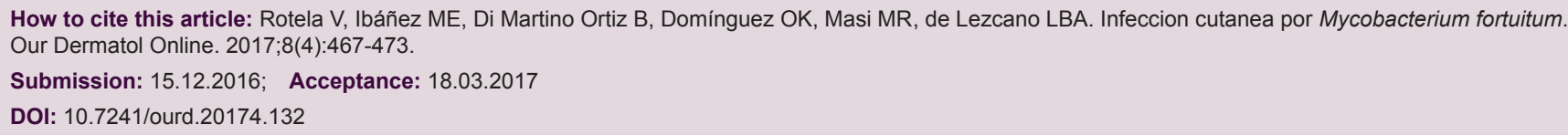


(BAAR: bacilo ácido alcohol resistente) y mantienen el primer colorante como carbolfucsina (tinción de Ziehl-Neelsen y Kinyoun) o fluorocromos (auraminarodamina).

Entre los factores de riesgo de infección se citan: tabaco (66\%), EPOC (42\%), infección por VIH (26\%) y alcoholismo (20\%), así como también procedimientos invasivos [1].

Para la confirmación diagnóstica se requiere de: Biopsia cutánea, cultivo del material de biopsia o de la secreción obtenida por aspiración, identificación de la micobacteria para establecer su sensibilidad, por lo cual los estudios bioquímicos y la PCR son los procedimientos más útiles. 2 Los avances en las técnicas de cultivo y moleculares han permitido que en la actualidad se hayan descrito cerca de 200 especies de micobacterias [4].

La clasificación de Runyon de 1954, modificada en 1974, está basada en las características de crecimiento de las micobacterias atípicas, según el tiempo de crecimiento y su capacidad de pigmentación.

Micobacterias de crecimiento lento: más de 7 días.

Micobacterias de crecimiento rápido: menos de 7 días.

Fotocromógenas: si producen colonias no pigmentadas en la oscuridad, pero pigmentadas si se exponen a la luz.

Escotocromógenas: si producen colonias amarillas o naranjas con y sin luz, incluso algunas incrementan los pigmentos tras la exposición, y no cromógenas, si son siempre no pigmentadas [1].

Son micobacterias atípicas de interés dermatológico (Tabla 1): Mycobacterium fortuitum, micobacteria atípica no pigmentada de crecimiento rápido, correspondiente al grupo IV según la clasificación de Runyon; produce en piel celulitis, abscesos, lesiones pápulo-pustulosas, nódulos o úlceras que drenan material sero-sanguinolento o purulento con zonas de necrosis subcutánea [1].

Tabla 1: Micobacterias atípicas de interés dermatológico

\begin{tabular}{ll}
\hline Especie & $\begin{array}{l}\text { Grupo de } \\
\text { runyon }\end{array}$ \\
\hline M. kansaii, M. marinum & I \\
M. scrofulaceum, M. szulgai, M. gordonae. & II \\
M. avium-intracellulare, M. haemophilum M. ulcerans & III \\
M. fortuitum, M. chelonae, M. abcessus & IV \\
\hline
\end{tabular}

\section{CASO CLINICO}

Mujer de 61 años, procedente de medio urbano, docente, portadora de púrpura pigmentosa crónica y sobrepeso, que consulta por lesión sobre elevada roja en pierna derecha de 2 meses de evolución, relacionada a picadura de insecto. 48 hs después viaja a México y luego de la inmersión en el mar, aumenta el número de lesiones, las mismas se ampollan, ulceran, y presentan secreción amarronada en una oportunidad, y purulenta persistentemente. Consulta en varias ocasiones con facultativos, recibiendo tratamientos con cefalexina, ciprofloxacina, y metronidazol, de manera irregular e incompleta, sin mejoría del cuadro.

\section{Examen Físico}

Placa eritemato-descamativa, ovalada, de $8 \times 5 \mathrm{~cm}$, límites netos, bordes irregulares, sobre la que asientan múltiples úlceras redondeadas cubiertas por costras hemáticas y melicéricas, rodeada de pápulas eritematosas satélite, asentada en cara anterior de tercio superior de pierna derecha (Figs. 1 y 2 ).

\section{Auxiliares del Diagnóstico}

- Frotis y cultivo de secreción purulenta, primer cultivo de piel, cultivo para hongos, PCR para

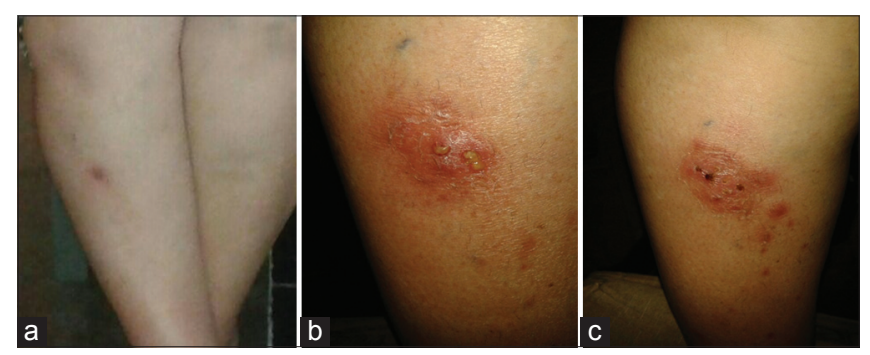

Figure 1: Clínica. (a) Lesión inicial: pápula eritematosa. B. A las 48 horas: placa eritematosa con pústulas (b), A los 2 meses: placa eritemato-descamativa con úlceras con costras hemáticas y melicéricas (c), en pierna derecha.

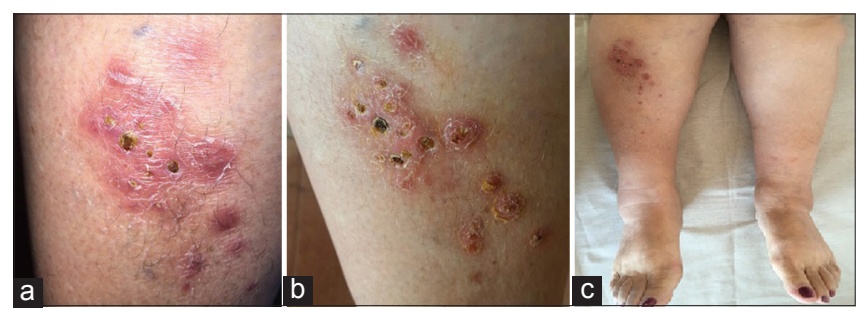

Figure 2: Clínica (a y b). Placa eritemato-descamatica, ovalada, de $5 \times 8 \mathrm{~cm}$ de dm, múltiples úlceras redondeadas cubiertas por costras hemáticas y melicéricas y pápulas eritematosas satélite, algunas con descamación blanquecina en collarete, localizadas en pierna derecha. (c) Visión panorámica de la lesión. 
Leishmania, reacción de Montenegro: Negativos. - Zielh-Neelsen para BAAR: Negativo.

\begin{tabular}{ll}
\hline $\begin{array}{l}\text { Frotis y cultivo de secreción } \\
\text { purulenta }\end{array}$ & $\begin{array}{l}\text { Leucocitos 20-30/campo } \\
\text { Hematíes: 10-20/campo } \\
\text { Gram: No se observan bacterias } \\
\text { No se obtiene desarrollo bacteriano a } \\
\text { los 7 días } \\
\text { Negativo }\end{array}$ \\
$\begin{array}{l}\text { Hisopado nasal para } \\
\text { Ecografía de piel y partes }\end{array}$ & $\begin{array}{l}\text { Engrosamiento difuso de piel y tejido } \\
\text { blandas pierna derecha }\end{array}$ \\
Radiografía de Tórax & $\begin{array}{l}\text { afectación ósea } \\
\text { Parámetros normales }\end{array}$ \\
\hline
\end{tabular}

Se procede a toma de material para histopatología y nuevos cultivos.

\section{Histopatología}

Grandes granulomas supurativos formados del centro a la periferia: 1. necrosis licuefactiva central, 2. empalizada de células inflamatorias (linfocitos, plasmocitos, macrófagos, algunos de apariencia epitelioide y células gigantes multinucleadas), y 3 . zona externa fibrosa (Figs. 3 y 4 ).

Técnicas especiales (PAS, GIEMSA, Ziehl Neelsen, PCR para Leishmaniasis, Reacción de Montenegro): negativas.

\section{Segundo Cultivo de Piel}

Se aísla micobacteria atípica no pigmentada de crecimiento rápido, se realiza detección molecular (Fig. 5).

\begin{tabular}{cl}
\hline Segundo Cultivo de Piel & Detección molecular de Micobacteria Atípica: \\
Se aísla micobacteria & se obtienen bandas de $234 / 118 / 88$ bp con \\
atípica no pigmentada & Bstell (Eco 911$)$ y de $147 / 124 / 63$ pb con HAE \\
de crecimiento rápido & III: Mycobacterium fortuitum; concordante con \\
& las características fenotípicas como velocidad \\
& de crecimiento y pigmentación de las colonias \\
& Método: Reacción en Cadena de \\
& Polimerasas asociada a Análisis de Patrón \\
& Enzimático (PRA) \\
\hline
\end{tabular}

\section{Metodología Microbiológica}

Fueron realizados estudios microbiológicos para micobacterias y hongos. Previa maceración de la muestra, para la búsqueda de micobacterias fue realizada una coloración de Ziehl Neelsen y el cultivo en medios de agar sangre y Lowestein Jensen e incubados a $35^{\circ} \mathrm{C}$ y, para el estudio micológico fue realizado un examen directo con $\mathrm{KOH}$ al $10 \%$ y cultivado en agar Sabouraud + Cloranfenicol, incubados tanto a 28 y $37^{\circ} \mathrm{C}$. El examen directo para hongos y la coloración de Ziehl Neelsen, resultaron negativas.

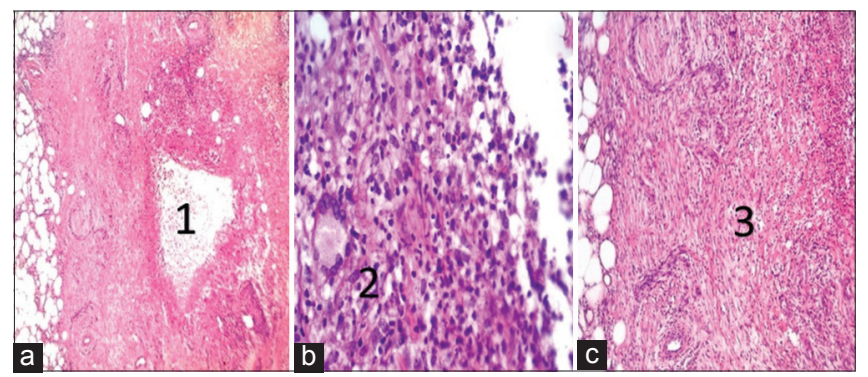

Figure 3: Histopatología. Grandes granulomas supurativos constituidos del centro a la periferia: (a) Necrosis licuefactiva central. (b) Empalizada de células inflamatorias (linfocitos, plasmocitos, macrófagos, algunos de apariencia epitelioide y células gigantes multinucleadas). (c) Fibrosis.
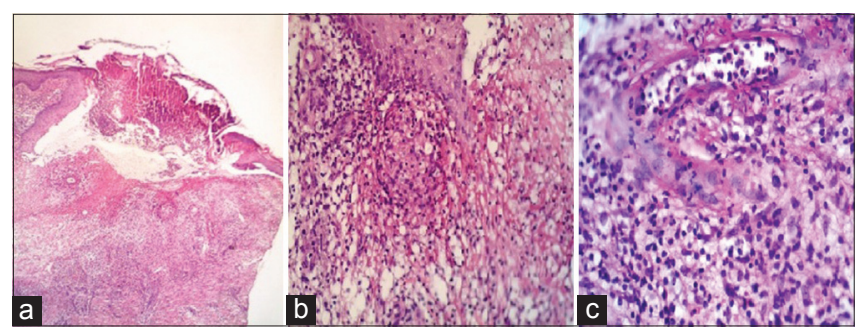

Figure 4: Histopatología. (a) Granulomas supurativos con extrusión del contenido purulento. (b) Granulomas en el borde de la zona abscedada. (c) Vasos dilatados y congestivos, con abundantes neutrófilos intraluminales y fenómeno de marginación típico de procesos inflamatorios agudos.

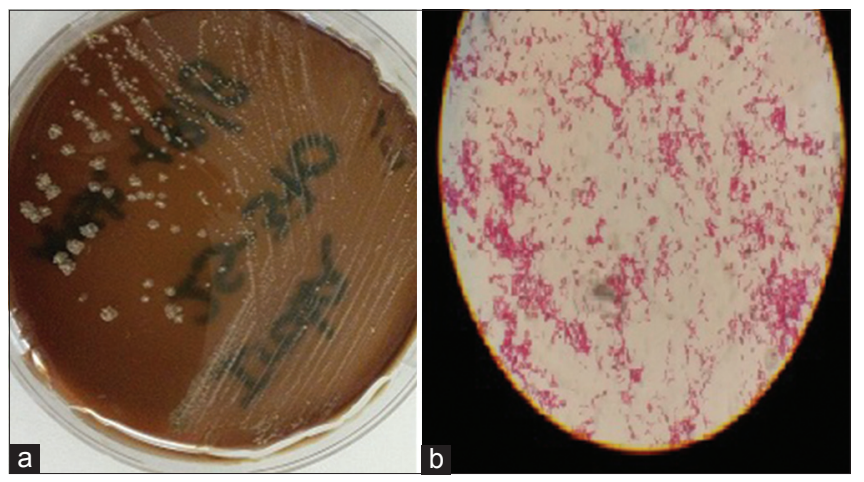

Figure 5: Microbiología. (a) Escasas colonias secas, de color crema compatibles con micobacterias de crecimiento rápido. (b) Coloración de Ziehl Neelsen: bacilos ácido alcohol resistentes (BAAR), finos y curvos.

En medio de Lowestein Jensen, a los 5 días se obtuvo desarrollo de escasas colonias secas, de color crema compatibles con micobacterias de crecimiento rápido, la que fue confirmada mediante la coloración de Ziehl Neelsen que a la observación microscópica mostró bacilos ácido alcohol resistentes(BAAR), finos y curvos.

La identificación a nivel de especie fue realizada mediante el método de reacción en cadena de la polimerasa asociada a restricción enzimática (PRA), utilizando la cepa de referencia M. tuberculosis 14323 
como control de amplificación e identificación. Se realizó extracción de ADN, según el protocolo descrito por van Soolingen et al [5], se prepararon diluciones de 50-100 ng/ul del ADN y se amplificó el gen que codifica la proteína heat shock (proteína de choque térmico) de 65-kDa utilizando los cebadores Tbll y Tbl2 descriptos por Telenti et al [6], seguido de la digestión del producto con enzimas de restricción HaeIII (Wako, Japón) y BstEII (BioLabs, UK) y la corrida electroforética en gel de poliacrilamida con marcador de peso molecular de 50 pb (Wako, Japón). Los tamaños de las bandas fueron determinados mediante el software KODAK (Kodak Digital Science1D Image Análisis Software). Las identidades de las cepas se obtuvieron introduciendo los tamaños de las bandas en la página web PRA-SITE [7], teniendo en cuenta además las características de velocidad de crecimiento y pigmentación. La micobacteria fue identificada como Mycobacterium fortuitum (Fig. 6).

Diagnóstico: Infección de Piel por Micobacteria atípica, Mycobacterium fortuitum.

\section{Tratamiento y Evolución}

Antibiograma: Buenos halos de inhibición frente a ciprofloxacina, amikacina, tetraciclina.

Se inicia tratamiento con ciprofloxacina $500 \mathrm{mg} / 12 \mathrm{hs}$ por 6-8 meses. Se realizan controles mensuales, notándose mejoría progresiva, disminución de lesiones y de signos inflamatorios, con resolución completa al octavo mes de tratamiento, con cicatrización e hiperpigmentación residual (Fig. 7).

\section{DISCUSION}

Las micobacterias no tuberculosas pueden causar infecciones de la piel y tejido celular subcutáneo generalmente después de un antecedente traumático en piel como inyecciones, laceraciones, depilación, contacto con acuarios e intervenciones quirúrgicas, como la mesoterapia, donde se citan con más frecuencia micobacterias de crecimiento rápido como $M$. chelonae, M. abscessus y $M$. fortuitum en el contexto de brotes epidémicos [8].

Las manifestaciones clínicas cutáneas son polimórficas, entre las que se encuentran: nódulos, fístulas, úlceras, abscesos, pápulas eritematosas, placas eritemato descamativas, lesiones eritemato violáceas, eritema nodoso, entre otras.

Las biopsias de las micobacteriosis cutáneas producen un gran espectro histológico sin correlación con la especie de micobacteria. Santa Cruz et al. describieron siete patrones: granulomas tuberculoides, abscesos, infiltrado difuso de histiocitos, paniculitis, inflamación crónica inespecífica, granulomas sarcoideos y nódulos pseudo reumatoides, predominando los dos primeros. Se han descrito multitud de formas intermedias y la aparición de varios patrones en la misma lesión $[9,10]$. En inmunodeprimidos el infiltrado inflamatorio tiende a ser más profundo y más difuso, con formación constante de abscesos, mientras que la formación de granulomas es más frecuente en inmunocompetentes. También destacan que la duración de la enfermedad guarda relación con el patrón histológico observado [10].

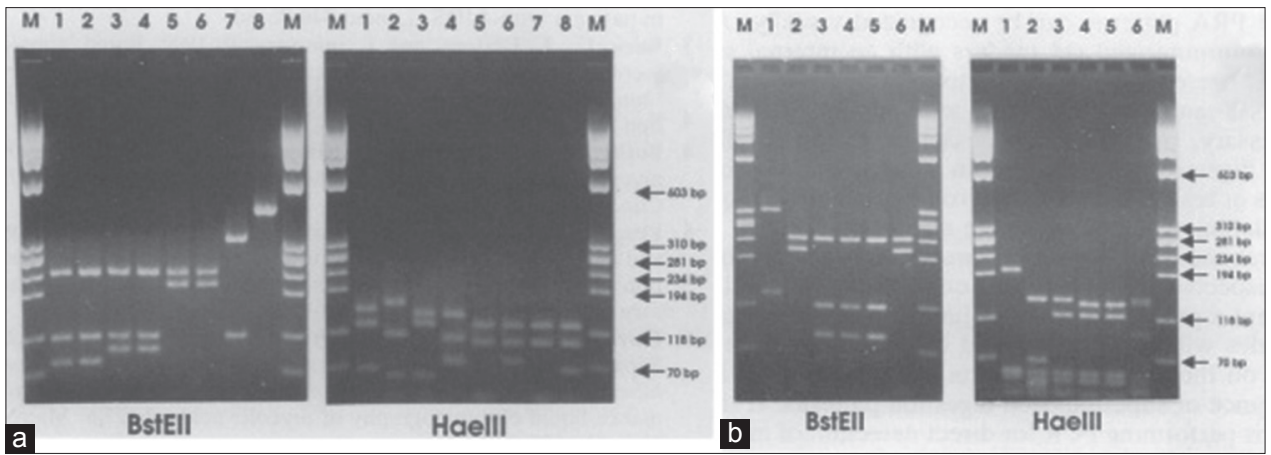

Figure 6: Biología Molecular: (a) PRA de las siguientes micobacterias de crecimiento lento seleccionadas: complejo M. tuberculosis (línea 1), M. gordonae (línea 2), M. intracellulare (línea 3), M. malmoense (línea 4), M. avium (línea 5), M. kansasii (línea 6), y M. szulgai (línea 8; no digerido con BstEII). Línea M, marcadores de masa molecular. Las micobacterias de crecimiento fastidioso tales como la recientemente descrita "M. genavense" (línea 7) también pueden ser identificadas por PRA. (b) La PRA permite la diferenciación de las siguientes cepas del complejo M. fortuitum al nivel de la subespecie: M. chelonae subsp. Chelonae (línea 1), M. chelonae subsp. Abscessus (línea 2), M. fortuitum subsp. Fortutum (línea 3), M. fortuitum subsp. Tercera variante ATCC 49403 y ATCC 49404 (líneas 4 y 5, respectivamente, patrones idénticos), y M. fortuitum subsp. Peregrinum (línea 6). Línea M, marcadores de masa molecular. ${ }^{6}$ 


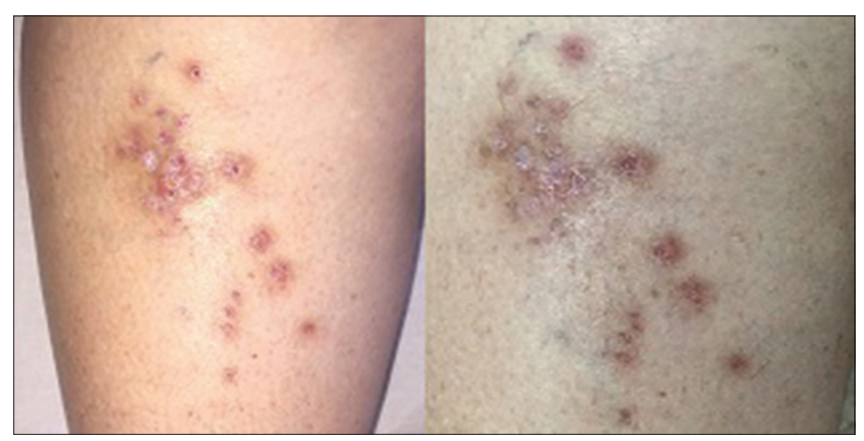

Figure 7: Evolución. Mejoría con disminución progresiva de las lesiones y signos inflamatorios, hasta resolución completa con cicatrización e hiperpigmentación residual.

Mycobacterium fortuitum fue descrito por primera vez como patógeno en las ranas, por lo que al ser reconocido como especie en 1923 se le dio el nombre de Mycobacterium ranae. La denominación de M. fortuitum le fue dada por Da Costa Cruz en 1938, cuando lo aisló de abscesos subcutáneos producidos por inyecciones de vitaminas. En 1955 fue perfectamente caracterizado por Gordon y Smith, pero no fue hasta 1972 cuando se aceptó definitivamente el nuevo nombre. Durante muchos años la cepa aislada por Da Costa Cruz se ha utilizado como cepa tipo de M. fortuitum biovar fortuitum. Las especies que integran el complejo M. fortuitum, a diferencia de las que integran el complejo $M$. chelonae, reducen los nitratos a nitritos y asimilan el hierro del citrato de hierro amoniacal dando lugar a colonias de color marrón oscuro en medio de Löwenstein-Jensen al que se ha incorporado este compuesto.

Son responsables de infecciones cutáneas polimórficas, queratitis, endoftalmitis, artritis supurativas, osteomielitis, endocarditis, meningitis, peritonitis, infección urinaria crónica, otitis media secundaria a la implantación de tubos de timpanostomía y bacteriemias asociadas a catéteres [11].

El tratamiento predeciblemente más eficaz frente a estos microorganismos es la escisión quirúrgica de todos los tejidos afectados. Desafortunadamente, esto no suele ser posible en la mayoría de casos y debe utilizarse tratamiento con antibióticos. M. fortuitum es generalmente sensible a la amikacina, cefoxitina, imipenem, ciprofloxacino, ofloxacino, sulfonamidas, claritromicina, y un $40 \%$ de las cepas son sensibles también a la doxiciclina. Se utilizan generalmente combinados en esquemas extensos, de varios meses de duración [12].

Siempre se debe sospechar infecciones por micobacterias no tuberculosas, en lesiones inflamatorias de curso crónico y con falta de respuesta a los tratamientos antibióticos habituales [4].

El diagnóstico correcto y el tratamiento precoz constituyen son los retos más importantes a los que nos enfrentamos con este tipo de microorganismos. El proceso diagnóstico en este caso ha sido largo y engorroso, y se ha tenido que recurrir a múltiples biopsias, y técnicas de avanzada Biología molecular para determinar la etiología de las lesiones cutáneas; el diagnóstico se realizó mediante Reacción en Cadena de Polimerasas asociada a Análisis de Patrón Enzimático (PRA).

El caso presentado está relacionado a un viaje y contacto con el mar y corales, sin historia previa de procedimientos quirúrgicos o invasivos, en paciente inmunocompetente, con buena evolución luego de tratamiento dirigido.

\section{CONCLUSIÓN}

Las micobacterias atípicas pueden causar infecciones de piel, tejido celular subcutáneo y otros aparatos y sistemas; generalmente son no patógenas en seres humanos, pero las infecciones están en aumento debido a condiciones de inmunosupresión. Se presenta el caso de una mujer de 61 años de edad, aparentemente inmunocompetente, que presenta lesión cutánea que empeora luego de la inmersión en el mar en México, recibe tratamiento infructuoso por dos meses, y tras múltiples biopsias para histopatología y cultivos, se detecta por biología molecular con Reacción en Cadena de Polimerasas asociada a Análisis de Patrón Enzimático, infección por Micobacterium fortuitum, se realiza tratamiento antibiótico dirigido con óptima resolución.

\section{BIBLIOGRAFÍA}

1. Valdés F, Cid A. Revisión. Micobaterias Atípicas. Actas Dermosifiliogr. 2004;95:331-57.

2. Di Martino B, Riveros R, Medina R, Rodríguez M, Knofelmacher O, Bolla L. Micobacteriosis atípica por Mycobacterium chelonae en una paciente inmunodeprimida. Presentación de un caso. Rev Panam Infectol. 2013;15:47-52.

3. Olivares L, Fandiño M, Fernández P, Pérez M, Maronna E. Infección cutánea por Mycobacterium chelonae. Dermatol Argent. 2011;17:446-50.

4. Gutiérrez De la Peña J, Ruíz Veramendi M, Montis-Suau A, Martı́nSantiago A. Tres casos de paniculitis por Mycobacterium abscessus posmesoterapia. Carta Científico-Clínica. Actas Dermosifiliogr. 2010;101:188-90.

5. Van Soolingen D, Hermans PW, de Haas PE, Soll DR, Van Embden JD. Occurrence and stability of insertion sequences 


\section{www.odermatol.com}

in Mycobacterium tuberculosis complex strains: evaluation of inseccion sequence-dependent DNA polymorphism as a tool in the epidemiology of tuberculosis. J Clin Microbiol 1991;19:2578-86.

6. Telenti A, Marchesi F, Balz M, Bally F, Boettger EC, Bodmer T. Rapid identification of mycobacteria to the species level by polymerase chain reaction and restriction enzyme analysis. J Clin Microbiol. 1993;31:175-8.

7. PRASITE. Identification of Mycobacteria. PRASITE. (online) 2007 September. (acceso 19 de octubre 2009). Disponible en: [http://app.chuv.ch/prasite].

8. Ramos A, Roustab G, Lucenac J, Dazad R. Aparición de nódulos subcutáneos después de aplicación de mesoterapia. Enferm Infecc Microbiol Clin. 2011;5:1-3.

9. Zaballos P, Araa M, Seralb C, Roderoa J, Grassa M, Agurruza J, et al. Foliculitis postdepilación por Mycobacterium chelonae. Actas Dermosifiliogr. 2002;93:259-62.
10. Santa Cruz DJ, Strayer DS. The histologic spectrum of the cutaneous mycobacterioses. Hum Pathol. 1982;13:485-95.

11. Bartralot R, Pujol RM, García-Patos V. Cutaneous infections due to nontuberculous mycobacteria: histopathological review of 28 cases. Comparative study between lesions observed in inmunosuppressed patients and normal hosts. J Cutan Pathol. 2000;27:124-9.

12. Ausina V, Lonca J. Mycobacterium fortuitum y otras micobacterias no pigmentadas de crecimiento rápido. Disponible en: www.seimc. org/control/revi_Micobac/pdf/mfortu.pdf 10/1/2007.

Copyright by Verónica Rotela, et al. This is an open-access article distributed under the terms of the Creative Commons Attribution License, which permits unrestricted use, distribution, and reproduction in any medium, provided the original author and source are credited.

Source of Support: Nil, Conflict of Interest: None declared. 